\title{
Reliability of Psychological Evaluation in Chronic Pain in an Interventional Pain Management Setting
}

Jose J. Rivera, MD, Vijay Singh, MD, Bert Fellows, MA, Vidyasagar Pampati, MSc, Kim S. Damron, RN, and

Carla D. McManus, RN, BSN

Background: Psychological disorders may be associated with poor pain related treatment outcomes. However, there may be limitations with studies evaluating the relationship between pain and psychopathology.

Objective: To assess the reliability of psychological evaluations in interventional pain management by MCMI-III ${ }^{\circledR}$ and $\mathrm{P}-3^{\circledR}$.

Study Design: Prospective evaluation of consecutive patients in an interventional pain management center.

Methods: Patients were evaluated using a DSM-IV-TR ${ }^{\circledR}$ questionnaire with a physician interview as an integral part of their comprehensive evaluation. In addition, all the patients participating in this study also underwent psychological evaluation with MCMI-III and P-3. A positive diagnosis of major depression or generalized anxiety disorder based on DSM-IV-TR criteria was consid-

Albert Schweitzer, the humanitarian, physician, and 1931 Nobel Laureate, elegantly described the nature of pain: "Pain is a more terrible lord of mankind than even death itself" (1). The Roman emperor and philosopher Marcus Aurelius wrote, "when unbearable pain destroys us... Recollect this, too, that many of our everyday discomforts are really pain in disguise such as drowsiness or want of appetite" (2). Further, the mutual inter-

From: Pain Management Center of Paducah, Paducah, Kentucky; and Pain Diagnotics Associates, Niagara, Wisconsin

Address correspondence:

Jose J. Rivera, MD

2831 Lone Oak Road

Paducah, KY 42003

E-mail: Jose@thepainmd.com

Disclaimer: There was no external funding in

preparation of this manuscript.

Conflict of Interest: None

Manuscript received on $4 / 12 / 2005$

Revision submitted on 6/20/2005

Accepted for publication on 8/14/2005 ered as the criterion standard.

All of the patients presented for treatment of chronic pain.

The data based on the criterion standard were compared with results of the diagnostic impression from the MCMI-III and the P-3 evaluation utilizing criteria for average, and above average, patient pain scores.

Results: Major depression was diagnosed in a total of 59 of 100 patients using DSM-IV-TR criteria, in 32 patients based on MCMI-III criteria, and in 55 patients based on $\mathrm{P}-3$ evaluations utilizing average pain patient criteria.

Generalized anxiety disorder was diagnosed in 55 patients by means of DSMIV-TR, 45 patients by MCMI-III, and 55 patients by $\mathrm{P}-3$ Profile utilizing average pain patient scores.

The specificity of MCMI-III was $100 \%$ with a sensitivity of $54 \%$ for diagnosis of depression; whereas it was $78 \%$ specificity and sensitivity for P-3, with average pain patient scores. For generalized anxiety disorder, specificity of MCMI-III was $89 \%$ with a sensitivity of $73 \%$ compared to specificity of $80 \%$ and sensitivity of $84 \%$ for average pain patient scores for P-3.

Conclusion: MCMI-III and $\mathrm{P}-3$ are highly specific in diagnosing depression and generalized anxiety disorder, with variable sensitivity. A DSM-IV-TR questionnaire evaluation incorporated into the pain management questionnaire, along with a short clinical interview, is a reliable means of assessing depression and anxiety in patients suffering with chronic pain.

Keywords: Psychiatric disorders, mental disorders, chronic pain, depression, generalized anxiety disorder, DSM-IV-TR, MCMIIII and P-3. action between physical pain and one's world view has been observed by philosophers and religious figures (3). Consequently, chronic pain is recognized as a complex phenomenon involving sensory, cognitive, affective, and behavioral components. Over the years, it has become increasingly evident that chronic pain is associated with high rates of recognized and unrecognized psychopathology (4).

Multiple reasons have been described to identify psychopathology in chronic pain patients. It has been shown that unrecognized and untreated psychopathology can significantly interfere with the successful management of chronic pain and patient rehabilitation (5-7), predictive of poor surgical outcomes $(6,8)$, and may increase pain intensity and disability, thus serving to propitiate pain-related dysfunction (8). A diagnosis of depression correlates with increased pain and less successful treatment outcomes (5,
$6,8)$. Anxiety has been found to decrease a patient's pain threshold and tolerance (9); also, anxiety and depression have been associated with a magnification of medical symptoms (10). In addition, emotional distress has been linked to physical symptoms through autonomic arousal, and vigilance (11), or somatic amplification (12). Consequently, prior to embarking on an appropriate treatment program - surgical, interventional, or behavioral an accurate assessment of a patient's condition is essential. Thus, an appropriate evaluation in interventional pain management should not only include an appropriate history and physical examination, and a functional assessment, but also a psychological assessment as well.

There is extensive evidence associating chronic pain and mental disorders (4-25). Multiple studies have shown that depression and anxiety are highly prevalent among persons with chronic pain. 
In samples evaluating chronic pain patients, rates of current major depression and anxiety can range from $15 \%$ to $54 \%$, significantly higher than the rate of $5 \%$ to $10 \%$ (without pain) found in the general population. Consequently, a considerable amount of research, using numerous psychological instruments, has been devoted to profiling the psychological and behavioral characteristics of chronic pain patients (22). Apart from developing a better understanding of the psychological mechanisms enhancing the chronic pain experience, ideally psychological profiles should be useful for classifying individual patients, determining treatment strategies, and predicting treatment response. Psychological screening seems to be most useful for those patients with lesser degrees of disc pathological findings, longer disability, and confounding economic issues (26).

Assessment of psychological status is achieved using interviews and self-report instruments. Ideally, psychological evaluation is performed by a trained psychologist or psychiatrist with interview and utilization of self-report instruments. This requires identification of patients requiring the services of a psychologist or a psychiatrist, plus an assessment of the availability and pain management interests of these specialists within the community. In addition, referring patients to a psychologist or psychiatrist outside the pain management setting may result in delays in the evaluation of psychological status from the initial pain management evaluation.

Finally, the feasibility of psychological services also depends highly upon financial resources. Consequently, the comprehensive psychological interview and evaluation not only are extensive and expensive, but are not covered by many insurers, resulting in multiple practical problems for interventional pain physicians, including delays in the treatment process.

Waddell and Turk (27) asserted that psychological diseases can not be assessed reliably by general physicians or surgeons by clinic impression alone. However, they referred to only the general clinical interview rather than to a psychological questionnaire that evaluated major depression based on criteria in the Diagnostic and Statistical Manual (DSM) of the American Psychiatric Association. Clinical trials have established the efficacy of anti-de- pressant medications and specific psychotherapies for depressive psychiatric and primary care patients when care is provided by trained personnel or under standardized protocols (28-33). But, there are no such studies available that address either the effectiveness of psychological status evaluation by interventional pain physicians or the effectiveness of anti-depressant and anti-anxiety therapy.

This evaluation was undertaken to evaluate the prevalence of depression and anxiety in chronic pain patients by a physician interview and application of $D i$ agnostic and Statistical Manual of Mental Disorders, Fourth Edition, Text Revi$\operatorname{sion}^{\mathrm{TM}}$ (DSM-IV-TR) criteria (36), and to compare the results with Millon Clinical Multiaxial Inventory ${ }^{\mathrm{TM}}$-III (MCMIIII) (34) and Pain Patient Profile Manu$\mathrm{al}^{\varpi}$ (P-3) (35).

\section{Methods}

A total of 100 consecutive patients were evaluated, all of whom presented with chronic pain to an interventional pain management practice. All patients were evaluated with history, physical examination, psychological evaluation, review of records, and the administration of a DSM-IV-TR questionnaire with a physician interview as an integral part of their comprehensive evaluation such as is provided to the majority of the patients presenting to this organization. In addition, all the patients participating in the study also underwent psychological evaluation with MCMI-III and P-3.

\section{Informed Consent}

All patients were provided an explanation of the purpose of the study and an opportunity for discussion. They were also advised that the psychological evaluation might result in a referral to psychological services and/or the administration of anti-depressant and anti-anxiety therapy. Informed consent was then obtained. Appropriate precautions were taken to protect the privacy and anonymity of all patients included in the study.

\section{Inclusion and Exclusion Criteria}

Inclusion criteria for patients in the study consisted of chronic pain of at least two year's duration, over 18 years of age, ability to comprehend and read in order to respond to MCMI-III and P-3 psychological evaluations, ability to understand written informed consent, and willingness to participate in the study.

Exclusion criteria included inability to understand or participate in psychological testing, inability to understand informed consent, and unwillingness to participate in the evaluation.

\section{Evaluation}

The study focused on two issues related to mental disorders: depression and anxiety. The psychological status of each patient was evaluated by obtaining a psychological history using a DSM-IV-TR criteria-based questionnaire for depression and anxiety; this was followed by a physician interview. Patients were also administered MCMI-III and P-3 evaluations.

The comprehensive evaluation includes multiple questions to determine depression and anxiety. Positive responses as determined by a DSM-IV-TR questionnaire and by personal interview were considered the diagnosis of major depression and generalized anxiety disorder. These criteria are listed in Tables 1 and 2.

MCMI is a commonly used test delineating psychological involvement in various medical syndromes. The MCMIIII is the latest version and it evaluates personality disorders and various clinical syndromes, including generalized anxiety disorder, depression, and somatoform disorder (34). The MCMI consists of 175 questions and does not require the presence of a psychologist for administration; it can be administered in outpatient settings in interventional pain practices.

The P-3 is an instrument for briefly assessing psychological characteristics known to affect pain perception and treatment response of patients in pain (35). The P-3 consists of 34 items that evaluate depression, anxiety, and somatization. A computerized profile is produced with an interpretation comparing the pain patient to a national sampling of patients in pain.

\section{Criterion Standard}

A patient was considered to have major depression or generalized anxiety disorder based on DSM-IV-TR criteria by questionnaire and personal interview (33). These data were compared with the results of MCMI-III and P-3. Diagnostic impression was utilized to compare results with MCMI-III. For the P-3, a diagnostic impression score 


\section{Table 1. Diagnostic criteria of major depressive episodes}

A. Five (or more) of the following symptoms have been present during the same 2-week period and represent a change from previous functioning; at least one of the symptoms is either (1) depressed mood or (2) loss of interest or pleasure.

Note: Do not include symptoms that are clearly due to a general medical condition, or mood-incongruent delusions or hallucinations.

(1) depressed mood most of the day, nearly every day, as indicated by either subjective report (e.g., feels sad or empty) or observation made by others (e.g., appears tearful). Note: In children and adolescents, can be irritable mood.

(2) markedly diminished interest or pleasure in all, or almost all, activities most of the day, nearly every day (as indicated by either subjective account or observation made by others)

(3) significant weight loss when not dieting or weight gain (e.g., a change of more than $5 \%$ of body weight in a month), or decrease or increase in appetite nearly every day. Note: In children, consider failure to make expected weight gains.

(4) insomnia or hypersomnia nearly every day

(5) psychomotor agitation or retardation nearly every day (observable by others, not merely subjective feelings of restlessness or being slowed down)

(6) fatigue or loss of energy nearly every day

(7) feelings of worthlessness or excessive or inappropriate guilt (which may be delusional) nearly every day (not merely self-reproach or guilt about being sick)

(8) diminished ability to think or concentrate, or indecisiveness, nearly every day (either by subjective account or as observed by others)

(9) recurrent thoughts of death (not just fear of dying), recurrent suicidal ideation without a specific plan, or a suicide attempt or a specific plan for committing suicide

B. The symptoms do not meet criteria for a Mixed Episode

C. The symptoms cause clinically significant distress or impairment in social, occupational, or other important areas of functioning.

D. The symptoms are not due to the direct physiological effects of a substance (e.g., a drug of abuse, a medication) or a general medical condition (e.g., hypothyroidism).

E. The symptoms are not better accounted for by Bereavement, i.e., after the loss of a loved one, the symptoms persist for longer than 2 months or are characterized by marked functional impairment, morbid preoccupation with worthlessness, suicidal ideation, psychotic symptoms, or psychomotor retardation.

Adapted from the Diagnostic and Statistical Manual for Mental Disorders. Fourth Edition, Text Revision ${ }^{\mathrm{TM}}$ (DSM-IV-TR). American Psychiatric Association. Washington: 2000.

\section{Table 2. Diagnostic criteria for Generalized Anxiety Disorder}

A. Excessive anxiety and worry (apprehensive expectation), occurring more days than not for at least 6 months, about a number of events or activities (such as work or school performance).

B. The person finds it difficult to control the worry.

C. The anxiety and worry are associated with three (or more) of the following six symptoms (with at least some symptoms present for more days than not for the past 6 months). Note: Only one item is required in children.

(1) restlessness or feeling keyed up or on edge

(2) being easily fatigued

(3) difficulty concentrating or mind going blank

(4) irritability

(5) muscle tension

(6) sleep disturbance (difficulty falling or staying asleep, or restless unsatisfying sleep)

D. The focus of the anxiety and worry is not confined to features of an Axis 1 disorder, e.g., the anxiety or worry is not about having a Panic Attack (as in Panic Disorder), being embarrassed in public (as in Social Phobia), being contaminated (as in Obsessive-Compulsive Disorder), being away from home or close relatives (as in Separation Anxiety Disorder), gaining weight (as in Anorexia Nervosa), having multiple physical complaints (as in Somatization Disorder), or having a serious illness (as in Hypochondriasis), and the anxiety and worry do not occur exclusively during Posttraumatic Stress Disorder.

E. The anxiety, worry, or physical symptoms cause clinically significant distress or impairment in social, occupational, or other important areas of functioning.

F. The disturbance is not due to the direct physiological effects of substance (e.g., a drug of abuse, a medication) or a general medical condition (e.g., hyperthyroidism) and does not occur exclusively during a Mood Disorder, a Psychotic Disorder, or a Pervasive Developmental Disorder.

Adapted from the Diagnostic and Statistical Manual for Mental Disorders. Fourth Edition, Text Revision ${ }^{\mathrm{TM}}$ (DSM-IV-TR). American Psychiatric Association. Washington, 2000. 
of ( $>54)$, and a threshold score of $>45$ was used for average chronic pain patients.

\section{Statistical Methods}

Data were recorded on a database using Microsoft ${ }^{\circledR}$ Access ${ }^{\circledR}$ Statistical Package for the Social Sciences (SPSS) software, version 9.0, was used to generate the frequency tables. The chi-squared statistic tween genders. Results were considered statistically significant if the $P$ value was less than 0.05 .

\section{RESULTS}

From October 2003 to April 2004, a total of 136 new patients with chronic pain were evaluated. Of these, $116 \mathrm{pa}$ tients were eligible to participate in the study, and met the inclusion criteria. Sixteen patients refused to participate. was used to test significant differences be-

\section{Demographic Characteristics}

As illustrated in Table 3, patients were predominantly female with an average age of 45 years, an average weight of 193.2 pounds, and an average height of 67.5 inches. Their average duration of pain was 9.4 years, and the majority provided with a history of traumatic event leading to their pain problems.

\section{Psychological Status}

Psychological status was evaluated by DSM-IV-TR questionnaire and personal interview as illustrated in Tables 4 and 5. Analyses were carried out with diagnostic impression with MCMI-III and P-3 results.

For P-3, a diagnostic impression required scores above those of average chronic pain patients ( $>55$ for anxiety and $>54$ for depression). In contrast, for MCMI-III, positive diagnostic impression was variable based on multiple factors;

Table 3. Demographic characteristics

\begin{tabular}{|l|l|c|}
\hline \multicolumn{2}{|l|}{} & $\begin{array}{c}\text { Number of patients in study } \\
(100)\end{array}$ \\
\hline \multirow{3}{*}{ Gender } & Men & $40 \%(40)$ \\
\cline { 2 - 3 } & Women & $60 \%(60)$ \\
\hline \multirow{3}{*}{ Weight (lbs.) } & Range & $21-79$ \\
\cline { 2 - 3 } & Mean \pm SD & $45.0 \pm 13.3$ \\
\hline \multirow{3}{*}{ Height (inches) } & Range & $90-347$ \\
\cline { 2 - 3 } & Mean \pm SD & $193.2 \pm 54.2$ \\
\hline \multirow{3}{*}{ Mode of onset } & Range & $59-76$ \\
\cline { 2 - 3 } & Mean \pm SD & $67.5 \pm 4.2$ \\
\hline \multirow{2}{*}{ Duration of pain (yrs) } & Non-traumatic & $44 \%(44)$ \\
\hline \multirow{2}{*}{ Average pain score (0-10) } & Traumatic & $56 \%(56)$ \\
\hline
\end{tabular}

Table 4. Results of psychological evaluation of depression by DSM-IV-TR, MCMI-III, and P-3

\begin{tabular}{|l|l|c|c|}
\hline \multicolumn{2}{|l|}{} & Depression & $\begin{array}{c}\text { Generalized Anxiety } \\
\text { Disorder }\end{array}$ \\
\hline DSM-IV-TR & $59 / 100$ & $55 / 100$ \\
\hline MCMI-III & Average pain patient scores $(>45)$ & $32 / 100$ & $45 / 100$ \\
\cline { 2 - 4 } & $\begin{array}{l}\text { Above average pain patient } \\
\text { s-3 profile }\end{array}$ & $22 / 100$ & $55 / 100$ \\
\hline
\end{tabular}

thus, only the diagnostic impression was utilized, rather than cut-off scores.

As expected, there were significant differences among two categories in P3 , namely average chronic pain patient scores and above average chronic pain patient scores (Table 4), leading to the diagnosis of anxiety in $21 \%$ vs $55 \%(p<0.001)$ and depression, $22 \%$ vs $55 \%(p<0.001)$.

\section{Major Depression}

Using DSM-IV-TR criteria, major depression was identified in 59 of the 100 patients in the study; 29 of the 59 patients were among the 38 patients in the study already on anti-depressant therapy, while 30 of those found to have major depression were from the 62 patients not on anti-depressant therapy (Table 5).

Under the MCMI-III evaluation, a total of 32 of the 100 patients in the study were identified with depression; of these, 18 were among the 38 patients already on anti-depressant therapy, and 14 were among the 62 patients not on anti-depressant therapy. There was a significant correlation (coefficient 0.572 ) between the DSM-IV-TR diagnosis and the MCMI-III diagnosis (Table 7).

On P-3 evaluation, only nine of the 38 patients already on anti-depressant therapy, and 13 of 62 patients not on anti-depressant therapy were diagnosed with major depression, for a total of 22 out of the 100 patients in the study. Consequently, the P-3 missed 37 patients identified with major depression using DSM-IV-TR criteria, and had a poor correlation when diagnostic impression was utilized. However, with P-3 scores of average chronic pain patients (>45), depression was present in 24 of 38 patients already on anti-depressant therapy, and in 31 of 55 patients not on anti-depressant therapy, with a total positive rate of $55 \%$. The correlation coefficient between MCMI-III and P-3 was 0.433 .

The data also showed that only $29 \%$ of the patients in the study identified positive for major depression under all three tests. When utilizing the average chronic pain criteria, the P-3 had a false-positive rate of $22 \%$. There were no false-positives with the MCMI-III evaluation or with the P-3 when utilizing above average chronic pain criteria (score of $>54$ ). In contrast, a false-negative rate of diagnosis was present in $46 \%$ based on MCMI-III testing, $22 \%$ when using the P-3 based on average pain patient criteria, and $63 \%$ by the P-3 based on above average pain patient criteria. 
Table 5. Results of evaluation of depression by DSM-IV-TR, MCMI-III, and P-3

\begin{tabular}{|c|c|c|c|c|c|c|c|}
\hline \multirow[b]{2}{*}{ Depression } & \multirow[b]{2}{*}{ DSM-IV-TR } & \multirow{2}{*}{\multicolumn{2}{|c|}{ MCMI-III }} & \multicolumn{4}{|c|}{ P-3 } \\
\hline & & & & \multicolumn{2}{|c|}{$\begin{array}{l}\text { Average pain } \\
\text { patient scores } \\
\qquad(>45)\end{array}$} & \multicolumn{2}{|c|}{$\begin{array}{l}\text { Above average pain } \\
\text { patient scores } \\
(>54)\end{array}$} \\
\hline Anti-depressant therapy (38) & $76 \%(29)$ & \multicolumn{2}{|c|}{$47 \%(18)$} & \multicolumn{2}{|c|}{$63 \%(24)$} & \multicolumn{2}{|c|}{$24 \%(9)$} \\
\hline No anti-depressant therapy (62) & $48 \%(30)$ & \multicolumn{2}{|c|}{$23 \%(14)$} & \multicolumn{2}{|c|}{$50 \%(31)$} & \multicolumn{2}{|c|}{$21 \%(13)$} \\
\hline Total (100) & $59 \%(59)$ & \multicolumn{2}{|c|}{$32 \%(32)$} & \multicolumn{2}{|c|}{$55 \%(55)$} & \multicolumn{2}{|c|}{$22 \%(22)$} \\
\hline \multirow{7}{*}{ Anti-depressant therapy } & & Positive & Negative & Positive & Negative & Positive & Negative \\
\hline & Positive (29) & 18 & 11 & 22 & 7 & 9 & 20 \\
\hline & Negative (9) & 0 & 9 & 2 & 7 & 0 & 9 \\
\hline & False-positive rate & \multicolumn{2}{|c|}{$0 \%$} & \multicolumn{2}{|c|}{$22 \%$} & \multicolumn{2}{|c|}{$0 \%$} \\
\hline & False-negative rate & \multicolumn{2}{|c|}{$38 \%$} & \multicolumn{2}{|c|}{$24 \%$} & \multicolumn{2}{|c|}{$69 \%$} \\
\hline & Specificity & \multicolumn{2}{|c|}{$100 \%$} & \multicolumn{2}{|c|}{$78 \%$} & \multicolumn{2}{|c|}{$100 \%$} \\
\hline & Sensitivity & \multicolumn{2}{|c|}{$62 \%$} & \multicolumn{2}{|c|}{$76 \%$} & \multicolumn{2}{|c|}{$31 \%$} \\
\hline \multirow{7}{*}{ No anti-depressant therapy } & & Positive & Negative & Positive & Negative & Positive & Negative \\
\hline & Positive (30) & 14 & 16 & 24 & 6 & 13 & 17 \\
\hline & Negative (32) & 0 & 32 & 7 & 25 & 0 & 32 \\
\hline & False-positive rate & \multicolumn{2}{|c|}{$0 \%$} & \multicolumn{2}{|c|}{$22 \%$} & \multicolumn{2}{|c|}{$0 \%$} \\
\hline & False-negative rate & & & & & & \\
\hline & Specificity & & & & & & \\
\hline & Sensitivity & & & & & & \\
\hline & & Positive & Negative & Positive & Negative & Positive & Negative \\
\hline & Positive (59) & 32 & 27 & 46 & 13 & 22 & 37 \\
\hline & Negative (41) & 0 & 41 & 9 & 32 & 0 & 41 \\
\hline Total & False-positive rate & & & & & & \\
\hline & False-negative rate & & & & & & \\
\hline & Specificity & & & & & & \\
\hline & Sensitivity & & & & & & \\
\hline
\end{tabular}

()$=$ Number of patients

The diagnosis of depression by MCMI-III specificity was $100 \%$, whereas sensitivity was $54 \%$. In contrast, the specificity and sensitivity was $78 \%$ with P-3 utilizing average pain patient scores. However, the specificity was $100 \%$ with an extremely low sensitivity of $37 \%$ with P3 when above average pain patient scores were utilized.

\section{Generalized Anxiety Disorder}

Using DSM-IV-TR criteria, generalized anxiety disorder was diagnosed in 18 of 22 patients on anti-anxiety therapy, and 37 of 78 patients not on anti-anxiety therapy for a total of 55 of 100 patients in the study.

MCMI-III evaluations provided a di- agnosis of anxiety for 14 of 22 patients already on anti-anxiety therapy, and for 31 of 78 patients not on anti-anxiety therapy for a total of $45 \%$ of the patients in the study being diagnosed with generalized anxiety disorder (Table 6). The correlation was significant with a correlation coefficient of 0.616 (Table 8).

P-3 evaluations using the above average (score of $>55$ ) criteria established diagnoses of anxiety for six of 22 patients already on anti-anxiety therapy, and for 15 of 78 patients not on anti-anxiety therapy, for a total of 21 of the 100 patients in the study. However, utilizing the P-3 scores of average chronic pain patients (score of $>45$ ) established that anxiety was present in 15 of 22 patients on anti-anxiety therapy, and present also in 40 of 78 patients not on anti-anxiety therapy, for a total of 55 of the 100 patients in the study evaluating positive for anxiety (Table 6). The correlation coefficient with DSM-IV-TR was 0.616 , and with MCMI-III it was 0.466 (Table 8).

The data showed that only $36 \%$ of the patients were evaluated as positive for anxiety by all three tests, in contrast to $45 \%$ to $55 \%$ positive rates with the individual tests. In addition, false-positive rates of $11 \%$ and $20 \%$ were observed with the MCMI-III and the P-3 when applying average pain patient scores; false-negative rates of $27 \%$ and $16 \%$ were observed with 
Table 6. Results of evaluation of generalized anxiety disorder by DSM-IV-TR, MCMI-III, and P-3

\begin{tabular}{|c|c|c|c|c|c|c|c|}
\hline \multirow[b]{2}{*}{ Generalized anxiety disorder } & \multirow[b]{2}{*}{ DSM-IV-TR } & & & \multicolumn{4}{|c|}{ P-3 } \\
\hline & & \multicolumn{2}{|c|}{ MCMI-III } & \multicolumn{2}{|c|}{$\begin{array}{l}\text { average pain patient } \\
\text { scores } \\
(>45)\end{array}$} & \multicolumn{2}{|c|}{$\begin{array}{l}\text { Above average pain } \\
\text { patient scores } \\
(>55)\end{array}$} \\
\hline Anti-anxiety therapy (22) & $82 \%(18)$ & \multicolumn{2}{|c|}{$64 \%(14)$} & \multicolumn{2}{|c|}{$68 \%(15)$} & \multicolumn{2}{|c|}{$27 \%(6)$} \\
\hline No anti-anxiety therapy (78) & $47 \%(37)$ & \multicolumn{2}{|c|}{$40 \%(31)$} & \multicolumn{2}{|c|}{$51 \%(40)$} & \multicolumn{2}{|c|}{$19 \%(15)$} \\
\hline Total (100) & $55 \%(55)$ & \multicolumn{2}{|c|}{$45 \%(45)$} & \multicolumn{2}{|c|}{$55 \%(55)$} & \multicolumn{2}{|c|}{$21 \%(21)$} \\
\hline \multirow{7}{*}{ Anti-anxiety therapy (22) } & & Positive & Negative & Positive & Negative & Positive & Negative \\
\hline & Positive (18) & 13 & 5 & 15 & 3 & 6 & 12 \\
\hline & Negative (4) & 1 & 3 & 0 & 4 & 0 & 4 \\
\hline & False-positive rate & \multicolumn{2}{|c|}{$25 \%$} & \multicolumn{2}{|c|}{$0 \%$} & \multicolumn{2}{|c|}{$0 \%$} \\
\hline & False-negative rate & \multicolumn{2}{|c|}{$28 \%$} & \multicolumn{2}{|c|}{$17 \%$} & \multicolumn{2}{|c|}{$67 \%$} \\
\hline & Specificity & \multicolumn{2}{|c|}{$75 \%$} & \multicolumn{2}{|c|}{$100 \%$} & \multicolumn{2}{|c|}{$100 \%$} \\
\hline & Sensitivity & \multicolumn{2}{|c|}{$72 \%$} & \multicolumn{2}{|c|}{$83 \%$} & \multicolumn{2}{|c|}{$33 \%$} \\
\hline \multirow{7}{*}{ No anti-anxiety therapy (78) } & & Positive & Negative & Positive & Negative & Positive & Negative \\
\hline & Positive (37) & 27 & 10 & 31 & 6 & 15 & 22 \\
\hline & Negative (41) & 4 & 37 & 9 & 32 & 0 & 41 \\
\hline & False-positive rate & \multicolumn{2}{|c|}{$10 \%$} & \multicolumn{2}{|c|}{$22 \%$} & \multicolumn{2}{|c|}{$0 \%$} \\
\hline & False-negative rate & & & & & & \\
\hline & Specificity & & & & & & \\
\hline & Sensitivity & & & & & & \\
\hline & & Positive & Negative & Positive & Negative & Positive & Negative \\
\hline & Positive (55) & 40 & 15 & 46 & 9 & 21 & 34 \\
\hline & Negative (45) & 5 & 40 & 9 & 36 & 0 & 45 \\
\hline Total & False-positive rate & & & & & & \\
\hline & False-negative rate & & & & & & \\
\hline & Specificity & & & & & & \\
\hline & Sensitivity & & & & & & \\
\hline
\end{tabular}

( ) = Number of patients

Table 7. Correlation of depression assessment

\begin{tabular}{|l|c|c|c|}
\hline & DSM-IV-TR & MCMI-III & $\begin{array}{c}\text { P-3 } \\
\text { Average pain }\end{array}$ \\
\hline DSM-IV-TR & 1.0000 & $0.616^{*}$ & $0.636^{*}$ \\
\hline MCMI-III & & 1.000 & $0.495^{*}$ \\
\hline P-3 (Average Pain) & & & 1.000 \\
\hline
\end{tabular}

Table 8. Correlation of Generalized Anxiety Disorder assessment

\begin{tabular}{|l|c|c|c|}
\hline & DSM-IV-TR & MCMI-III & $\begin{array}{c}\text { P-3 } \\
\text { Average pain }\end{array}$ \\
\hline DSM-IV-TR & 1.0000 & $0.554^{*}$ & $0.572^{*}$ \\
\hline MCMI-III & & 1.000 & $0.491^{*}$ \\
\hline P-3 (Average Pain) & & & 1.000 \\
\hline
\end{tabular}

${ }^{\star} \mathbf{p}<0.001$ the MCMI-III and the P-3 when utilizing average pain patient scores.

The data also showed that specificity and sensitivity of MCMI-III in diagnosing generalized anxiety disorder was $89 \%$ and $73 \%$, compared to $80 \%$ and $84 \%$ with P-3 utilizing average pain patient scores. In contrast, utilizing above average pain patient scores for P-3 specificity was $100 \%$, however, with a low sensitivity of $38 \%$.

\section{Combined Depression and Anxiety}

The evaluation also showed that 45 of 100 patients suffered with combined major depression and generalized anxiety disorder under DSM-IV-TR criteria (Table 9). 
Table 9. Combination of Depression and Generalized Anxiety Disorder by DSM-IV-TR criteria

\begin{tabular}{|c|c|c|c|c|}
\hline & & \multicolumn{2}{|c|}{ Anxiety } & \multirow{2}{*}{ Total } \\
\hline & & Negative & Positive & \\
\hline \multirow{2}{*}{ 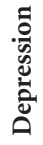 } & Negative & 35 & 6 & 41 \\
\hline & Positive & 10 & 49 & 59 \\
\hline \multicolumn{2}{|c|}{ Total } & 45 & 55 & 100 \\
\hline
\end{tabular}

\section{DisCusSION}

Among the 100 patients in the study, based on DSM-IV-TR criteria, this prospective evaluation established a diagnosis of major depression in 59\% of the patients, generalized anxiety disorder in $55 \%$, and combined diagnoses in $49 \%$. The results of DSM-IV-TR evaluations correlated well with MCMI-III evaluations when considering diagnoses of major depression and generalized anxiety disorder having correlation coefficients of 0.616 and 0.572 . Both with major depression and generalized anxiety disorder, the correlation was poor when utilizing the P3 evaluation applying above average criteria. However, the correlation improved significantly with the application of average scores of pain patients yielding correlation coefficients with DSM-IV-TR of 0.636 with depression and 0.572 with anxiety. Further, the P-3 average pain scores correlated well with the MCMI-III with correlation coefficients of 0.495 for depression and 0.491 for anxiety.

The results demonstrated that major depression and generalized anxiety disorder are commonly seen in patients suffering with chronic pain, even among those on anti-depressant and/or anti-anxiety therapy. Fourteen patients in the study were receiving a combination of anti-depressant therapy and anti-anxiety therapy; 38 patients were receiving anti-depressant therapy; and 21 patients were receiving anti-anxiety therapy. This study establishes the reliability of evaluations for depression and generalized anxiety disorder based on DSM-IV-TR criteria utilizing a questionnaire and simple interview, MCMI-III evaluations, or P-3 evaluations. Further, DSM-IV-TR criteria identified depression and generalized anxiety disorder in most of those patients already on anti-depressant therapy and anti-anxiety therapy. Despite good correlations be- tween the MCMI-III and the P-3, and the ability of both tests to identify depression and anxiety, significant rates of false-positives and false-negatives were observed for anxiety, whereas for depression, mainly false-negative rates were observed.

The accuracy of any diagnostic test is essential, but variable, just as diagnostic tests vary in sensitivity, specificity, and quality. False-positive rates (how often patients without a condition will have positive results) and false-negative rates (how often patients with disease will have a negative result) are crucial. Placebo-responses to psychological evaluations are probably least applicable since no experimental drug is provided, but even so, placebo-response may not be completely ruled out. A degree of uncertainty exists in clinical medicine, and in all diagnostic testing applied to individual patients.

In this study, false-positive rates of depression were $22 \%$ with the P-3 when using average chronic pain patient scores. However, there were no false-positives observed with the MCMI or the P3 when utilizing above average chronic pain patient scores. In contrast falsenegative rates were $46 \%$ with the MCMI, $22 \%$ with the P-3 when using average pain patient scores, and $63 \%$ when using above average pain patient scores. The results of this study show that the MCMIIII is highly specific (100\%) with a sensitivity of $46 \%$. Similarly, the P-3 when utilizing above average pain patient scores is $100 \%$ specific but with a sensitivity of $37 \%$. When utilizing average pain patient scores, the P-3 demonstrated $78 \%$ sensitivity and $78 \%$ specificity. In contrast, for anxiety the MCMI-III showed a sensitivity of $73 \%$ and a specificity of $89 \%$. The P-3 evaluation when using average pain patient scores showed $80 \%$ specificity and $74 \%$ sensitivity. However, while using above average pain patient scores, the
P-3 specificity was $100 \%$ with a sensitivity of $38 \%$.

The accuracy of diagnostic testing is best determined by its sensitivity (positive when condition is present), specificity (negative when condition is absent), and by comparing it to a criterion standard. DSM-IV-TR criteria is considered to be the criterion standard for this study, as diagnosis is made based on these criteria, and all psychological tests are constructed based on these criteria.

The psychological status of chronic pain patients was evaluated in multiple studies. Manchikanti et al $(21,23,24)$ showed the prevalence of major depression to be $22 \%$ to $53 \%$ among patients, and generalized anxiety disorder to be present in $20 \%$ to $49 \%$ of patients. Polatin et al (21) showed the prevalence of depressive disorders in $49 \%$ of patients and anxiety disorders in 15\% of patients.

McWilliams et al (13) evaluated depression and anxiety disorders associated with three pain conditions - arthritis, migraine, and back pain - from a nationally representative sample. Logistic regression analyses revealed significant positive associations between each pain condition and the psychiatric disorders with odds ratios ranging from 1.48 to 3.86 . However, the prevalence of depression in that study ranged from $18.2 \%$ in arthritis, to $21.0 \%$ in back pain and $28.5 \%$ in migraine. Similarly generalized anxiety disorder was also seen in $5.6 \%$ of the patients with arthritis, $6.2 \%$ of the patients with back pain, and $9.1 \%$ of the patients with migraine.

The present study shows results similar to previous studies. This study shows the value of psychological evaluation utilizing DSM-IV-TR criteria with a simple questionnaire and physician interview as having significant value. In addition, the results of this study show that the MCMIII and P-3 may not be superior, and/or may not even equal this type of evaluation. This study also demonstrated the appropriateness of diagnostic assessment in interventional pain management. It also dispels the myth that physicians are incapable of accurately evaluating patient psychological status as described by Waddell and Turk (27).

The MCMI-III is an evolving assessment tool, distinguished from other inventories with its relative brevity, theoretical anchoring, structural characteristics, and the use of a three-stage validation framework. While its comput- 
er-based reports register high levels of satisfaction with users as to their overall quality and their correspondence to independently-derived clinical observations and judgments, nevertheless, clinicians who use the interpretative report should not be lulled into uncritical acceptance (34). Consequently, all the reports should routinely compare the statements generated against independent clinical evidence.

The P-3 is an instrument for briefly assessing psychological characteristics known to affect pain perception and treatment response for patients in pain. With its simplicity of format and content, the P-3 is considered to offer several advantages to pain professionals: the administration of the P-3 takes approximately 15 minutes of an initial clinical evaluation; it has clinical scales for depression, anxiety, and somatization; and of specific advantage, the intent of the P-3 is to compare the symptoms of an individual pain patient to the symptoms of an average pain patient (35).

Even with simplicity and relative inexpensiveness of the above tests and numerous other tests available in today's market, interventional pain physicians continue to be faced with multiple issues related to reliability, cost, and time. However, all of the tests have been developed based on the Diagnostic and Statistical Manual for Mental Disorders (DSM) criteria for depression, anxiety, somatization, and various other psychological disorders (36). Depression and anxiety are the two major issues in interventional pain management that can be managed with medical therapy or psychotherapy. DSM criteria may also be applied in the form of a questionnaire or personal interview during a patient's initial evaluation. The relative superiority of either MCMI or P-3 have not been proven but they may hold potential benefits such as ease of administration, time savings, cost savings, and simultaneous administration of psychological evaluations, as well as the elimination of a distant and separate evaluation.

Our study may be criticized by traditionalists because it did not utilize a psychiatrist or psychologist for evaluation and screening purposes, and also possibly because it did not include a physician interview in conjunction with administration of the MCMI-III and P-3 evaluations. Since the purpose of this evaluation was to compare the DSM-IVTR questionnaire combined with a clinical interview by an evaluating physician to the MCMI-III and P-3, we feel that it is appropriate. In clinical practice, this approach is essential and cost effective in terms of maintaining appropriate access and managing issues of psychological importance, along with managing pain issues.

Secondly, we may be criticized for not using the MMPI evaluation as part of this study. We did not include it because the MMPI consists of 566 questions, is very expensive, and can only be administered by psychological professionals.

Thirdly, criticism of this study may focus on its small sample as opposed to large community samples and diagnostic interviews that might more adequately investigate the associations between pain conditions and psychiatric disorders $(13,19)$. However, these requirements are financially and logistically demanding (37). Multiple authors have taken advantage of data derived from large mental health surveys that included general health and disability questions $(13,19,37)$. McWilliams et al $(13,19)$ showed significant associations between arthritis, back pain, and migraine with each of the mood and anxiety disorders considered. Given the lack of attention to anxiety disorders in the pain literature it was particularly noteworthy that associations between multiple pain conditions and several anxiety disorders were stronger than were the associations between various painful conditions and depression $(38,39)$. Various limitations have been presented concerning the reliability and validity of large samples that employ diagnostic interviews to assess the presence of a wide range of psychiatric disorders and their correlation to pain $(13,19,25,37-39)$. The prevalence of these disorders in the national population are low; consequently, these samples are not representative of patients presenting to tertiary referral centers such as interventional pain management centers (40).

\section{ConcLusion}

This study showed the prevalence of depression in chronic pain patients utilizing DSM-IV-TR criteria was 59\%, when using the MCMI-III it was $32 \%$, and when using the P-3 (average pain patient scores of $>45$ ) it was $55 \%$. Gener- alized anxiety disorder was seen in 55\% of the patients when utilizing the DSMIV-TR criteria, $45 \%$ when utilizing the MCMI-III, and 55\% when utilizing the P-3 (average pain patient scores of $>45$ ). The MCMI-III and P-3 (average pain patient scores) were reliable in evaluating both major depression and generalized anxiety disorder.

We conclude that a DSM-IV-TR questionnaire evaluation incorporated into the pain management questionnaire, along with a short clinical interview, is a reliable means of assessing depression and anxiety in patients suffering with chronic pain.

\section{AUtHOR AfFILIATION:}

Jose J. Rivera, MD

Interventional Pain Physician

Pain Management Center of Paducah

2831 Lone Oak Road

Paducah, KY 42003

E-mail: Jose@thepainmd.com.

Vijay Singh, MD

Medical Director

Pain Diagnostics Associates

1601 Roosevelt Rd.

Niagara, WI 54151

E-mail:vs@netnet.net

\section{Bert Fellows, MA}

Clinical Psychologist

Pain Management Center of Paducah 2831 Lone Oak Road

Paducah, KY 42003

E-mail: bert@thepainmd.com

Vidyasagar Pampati, MSc

Statistician

Pain Management Center of Paducah

2831 Lone Oak Road

Paducah, KY 42003

E-mail: sagar@thepainmd.com

Kim S. Damron, RN

Nursing Administrator

Ambulatory Surgery Center

2831 Lone Oak Road

Paducah, KY 42003

E-mail: kim@thepainmd.com

Carla D. McManus, RN, BSN

Assistant Nursing Administrator

Ambulatory Surgery Center

2831 Lone Oak Road

Paducah, KY 42003

E-mail: carla@thepainmd.com 


\section{References}

1. Schweitzer A. On the Edge of Primeval Forest. MacMillan, New York: 1931, p 62.

2. Aurelius M. Meditations, Book VII. Harvard University Press, Cambridge: 1930, Verse 33 .

3. Burton R. The Anatomy of Melancholy. New York Review of Books, New York: 2001.

4. Dersh J, Gatchel RJ, Polatin P. Chronic spinal disorders and psychopathology: Research findings and theoretical considerations. Spine 2001; 1:88-94.

5. Bair MJ, Robinson RL, Katon W, Kroenke K. Depression and pain comorbidity: a literature review. Arch Intern Med 2003; 163: 2433-2445.

6. Epker J, Block AR. Presurgical psychological screening in back pain patients: $A$ review. Clin J Pain 2001; 17:200-205.

7. Gatchel RJ. Psychological disorders and chronic pain: cause and effect relationships. In Gatchel RJ, Turk DC, (eds). Psychological approaches to pain management: a practitioner's handbook. Guilford Publications, New York; 1996, pp 33-54.

8. Burns J, Johnson B, Mahoney N, Devine J, Pawl R. Cognitive and physical capacity process variables predict long-term outcome after treatment of chronic pain. J Clin Consult Psychiatry 1998; 66:434-439.

9. Cornwal A, Doncleri DC. The effect of experimental induced anxiety on the experience of pressure pain. Pain 1988; 35:105113

10. Katon W. The impact of major depression on chronic medical illness. Gen Hosp Psychiatry 1996; 18:215-219.

11. Sullivan M, Katon W. Somatization: the path between distress and somatic symptoms. Am Pain Soc J 1993; 2:141-149.

12. Barsky A, Klerman G. Overview: hypochondriasis, bodily complaints, and somatic styles. Am J Psychiatry 1983; 140: 273-283.

13. McWilliams LA, Goodwin RD, Cox BJ. Depression and anxiety associated with three pain conditions: results from a nationally representative sample. Pain 2004; 111:77-83.

14. Gatchel RJ. A biopsychosocial overview of pretreatment screening of patients with pain. Clin J Pain 2001; 17:192-199.

15. Rush AJ, Polatin P, Gatchel RJ. Depression and chronic low back pain. Spine 2000; 25:2566-2571.

16. Fishbain DA, Cutler R, Rosomoff HL, Rosomoff RS. Chronic pain associated depression: Antecedent or consequence of chronic pain? A review. Clin J Pain 1997; 13:116-137.

17. Macfarlane GJ, Morris S, Hunt IM, Benjamin S, McBeth J, Papageorgiou AC, Silman AJ. Chronic widespread pain in the community: The influence of psychological symptoms and mental disorder on healthcare seeking behavior. I Rheumatol 1999; 26:413-419.

18. Von Korff M, Le Resch L, Dworkin S. First onset of common pain symptoms: A prospective study of depression as a risk factor. Pain 1993; 55:251-258.

19. McWilliams LA, Cox BJ, Enns MW. Mood and anxiety disorders associated with chronic pain: an examination in a nationally representative sample. Pain 2003; 106: 127-133.

20. Polatin PB, Kinney RK, Gatchel RJ, Lillo E, Mayer TG. Psychiatric illness and chronic low back pain: The mind and the spine which goes first? Spine 1993; 18:66-71.

21. Manchikanti L, Pampati VS, Fellows B, Beyer CD, Damron KS, Barnhill RC, Burks T. Characteristics of chronic low back pain in patients in an interventional pain management setting: A prospective evaluation. Pain Physician 2001; 4:131-142.

22. Davis PJ, Reeves JL, Hastie BA, Graff-Radford SB, Naliboff BD. Depression determines illness conviction and pain impact: A structural equation modeling analysis. Pain Med 2000; 1:238-246.

23. Manchikanti L, Fellows B, Pampati VS, Damron KS, Beyer CD, Barnhill RC. Comparison of psychological status of chronic pain patients with general population. Pain Physician 2002; 5:40-48.

24. Manchikanti L, Pampati VS, Damron KS, Beyer CD, Barnhill RC. Evaluation of psychological status in chronic low back pain: Comparison with general population. Pain Physician 2002; 5:149-155.

25. Currie S, Wang J. Chronic back pain and major depression in the general Canadian population. Pain 2004; 107:54-60.

26. Carragee EJ. Psychological screening in the surgical treatment of lumbar disc herniation. Clin J Pain 2001; 17:215-219.

27. Waddell G, Turk DC. Clinical assessment of low back pain. In Turk DC, Melzack R (eds). Handbook of Pain Assessment. First Edition. The Guilford Press, New York: 1992, pp 15-36.

28. Depression Guidelines Panel. Depression in Primary Care, I: Detection and Diagnosis. Rockville, MD. US Dept of Health and Human Services, 1993. US Public Health Service, Agency for Health Care Policy and Research publication 93-0550.
29. Depression Guidelines Panel. Depression in Primary Care, II: Treatment of Major Depression. Rockville, MD, US Dept of Health and Human Services; 1993. US Public Health Service, Agency for Health Care Policy and Research publication 93-0551.

30. Schulberg HC, Block MR, Madonia MJ, Scott CP, Rodriguez E, Imber SD, Perel J, Lave J, Houck PR, Coulehan JL.. Treating major depression in primary care practice: 8-month clinical outcomes. Arch Gen Psychiatry 1996; 53:913-919.

31. Malt UF, Robak OH, Madsbu HP, Bakke O, Loeb M Bakke O, Loeb M. The Norwegian Naturalistic Treatment Study of Depression in General Practice (NORDEP)-I: Randomized double blind study. BMJ 1999; 318:1180-1184.

32. Attikson CC, Zich JM. Depression in Primary Care: Screening and Detection. Routledge, New York: 1990.

33. Wells KB, Sherbourne C, Shoenbaum M, Duan N, Meredith L, Unutzer J, Miranda J, Carney MF, Rubenstein LV.. Impact of disseminating quality improvement programs for depression in managed primary care. A randomized controlled trial. JAMA 2000; 283:212-220.

34. Millon T. MCMI-III Manual, ed 2, National Computer Systems, Inc., Minneapolis: 1997.

35. Tollison CD, Langley JC. Pain Patient Profile $(P-3)$ Manual. National Computer Systems, Inc., Minneapolis: 1995.

36. Diagnostic and Statistical Manual for Mental Disorders. Fourth Edition, Text Revision (DSM-IV $\left.{ }^{\circledR}-\mathrm{TR}\right)$. American Psychiatric Association. Washington: 2000.

37. Wells KB, Golding JM, Burnam M. Psychiatric disorder in a sample of the general population with and without medical conditions. Am / Psychiatry 1988; 145:976981.

38. Breslau N, Davis GC. Migraine, physical health and psychiatric disorder: a prospective epidemiology study in young adults. J Psychiatr Res 1993; 27:211-221.

39. Merikangas KR, Angst J, Isler H. Migraine and psychopathology: results of the Zurich cohort study of young adults. Arch Gen Psychiatry 1990; 47:849-853.

40. Kessler RC, McGonagle KA, Zhao S, Nelson $\mathrm{CB}$, Hughes M, Eshleman S, Wittchen HU, Kendler KS. Lifetime and 12-month prevalence of DSM-III-R psychiatric disorders in the United States. Results from the National Comorbidity Survey. Arch Gen Psychiatry $1994 ; 51: 8-19$. 
